\title{
Peranan Komunitas Berbudaya Toraja Sebagai Penyangga Kedatuan Luwu
}

M. Nur

Keywords: history, culture, historiography, custom, community, involvement

\section{How to Cite:}

Nur, M. (2006). Peranan Komunitas Berbudaya Toraja Sebagai Penyangga Kedatuan Luwu. Berkala Arkeologi, 26(2), 70-84. https://doi.org/10.30883/jba.v26i2.934

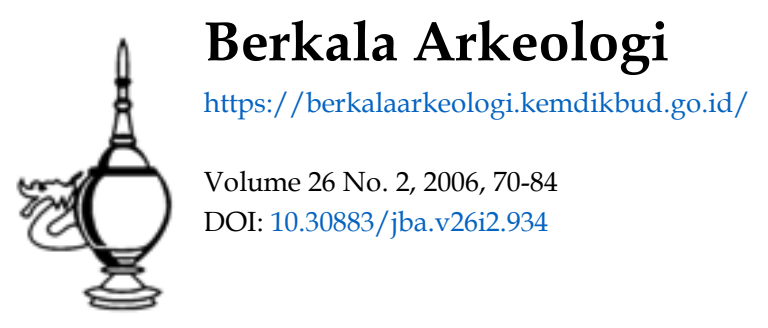




\title{
PERANAN KOMUNITAS BERBUDAYA TORAJA SEBAGAI PENYANGGA KEDATUAN LUWU
}

\author{
M.Nur*
}

\section{Pengantar}

Dalam historiografi lokal, Luwu merupakan salah satu kerajaan yang telah mendapat perhatian cukup besar dibandingkan dengan kerajaan lain. Bila kita harus menyimpulkan beberapa bacaan tentang Kedatuan Luwu, kalimat yang tepat adalah Kerajaan Luwu merupakan kerajaan yang patut diperhitungkan dalam historiografi Nusantara, paling tidak pada abad ke-14, mendahului kerajaan Gowa di pesisir barat Sulawesi Selatan. Meskipun kita sudah sampai pada kesimpulan tersebut tanpa pernah mendapat bantahan secara berarti, bukan berarti bahwa perspektif yang selama ini dipakai untuk meneropong Luwu tidak memiliki kelemahan.

Kita memang harus berterima kasih kepada Caldwell (1995 dan 1998) karena analisis filologinya terhadap teks-teks Bugis yang sampai pada kesimpulan bahwa aksara Bugis telah dikembangkan pada sekitar tahun $1300 \mathrm{M}$. Lebih jauh, hasil pengamatannya pada daftar raja-raja Luwu menyimpulkan bahwa penguasa Luwu pertama -yang merupakan kerajaan Bugis-juga memulai pemerintahannya sekitar 1300 M. Selanjutnya, dapat dikatakan bahwa kemajuan signifikan dalam pengungkapan sejarah Kedatuan Luwu adalah sumbangan perspektif dan data dari penelitian The Origins of Complex Society in South Sulawesi (Oxis Project) tahun 1998-1999 yang minimal telah menghasilkan kronologi dan beberapa aspek yang telah memungkinkan Kedatuan Luwu berkembang. Cuplikan beberapa data Oxis Project yang dirangkum dalam buku Kedatuan Luwu pertama (Fadillah dan Sumantri, 2000) menurut saya paling tidak telah menyajikan perspektif penelitian masa depan yang lebih luas dan sekaligus menjauhkan kita dari interpretasi sejarah yang berlebihan serta memperingatkan kepada kita untuk hati-hati menggunakan sumber tertulis dalam merekonstruksi Kedatuan Luwu. Sekali lagi, Ian Caldwell 
dengan tegas menyatakan bahwa Sure Lagaligo tidak dapat dijadikan sebagai sebuah sumber sejarah bagi rekonstruksi Kedatuan Luwu karena unsur anakronisme pada hampir semua penceritaannya (Caldwell, 2003). Walaupun demikian, saya sangat yakin bahwa Sure Lagaligo dapat membantu memudahkan pekerjaan retrieval dalam memperoleh gambaran sejarah Kedatuan Luwu. Terakhir, karya Mahmud (2002) yang sangat baik dan impresif tentang aspek-aspek simbolis dan filosofis yang melatarbelakangi terbentuknya tata kota kuno Palopo telah membantu kita memahami teritori inti Kedatuan Luwu.

Gambaran beberapa hasil penelitian di atas sebenarnya adalah landasan sangat baik untuk meneropong Kedatuan Luwu lebih luas. Walaupun demikian, dapat pula saya katakan di sini bahwa dalam upaya rekonstruksi Kedatuan Luwu secara menyeluruh, seluruh data tentang Kedatuan Luwu juga harus mendapat perlakuan analisis yang sama. Dalam kerangka pikir ini, saya ingin mengatakan bahwa apa yang telah dihasilkan sekarang masih perlu dilebarkan ke seluruh komunitas penunjang. Sesungguhnya Kedatuan Luwu sangat kompleks, tidak dapat dipahami hanya dengan mengandalkan data yang ada pada pusat kedatuan saja tetapi sampai ke semua wilayah penyangga yang luas. Inilah yang saya maksudkan pada paragraf awal sebagai kelemahan perspektif.

Menyangkut wilayah penyangga Kedatuan Luwu, sebuah seri pemberitaan menarik oleh Braam Morris (1888) tentang wilayah Kedatuan Luwu akan mengantar kita untuk memulai napak tilas, terutama catatannya tentang bentangan geografis dan demografis Luwu sebagai berikut.

Negeri Luwu berbatas di sebelah selatan dengan Pitumpanuwa yang termasuk dalam wilayah Bone, Wajo dan Poleang serta wilayah Buton yang terletak di dataran Sulawesi. Di sebelah barat dengan Wajo, Ajatappareng, Masenrempulu dan kerajaan-kerajaan Mandar; Di sebelah utara dengan Palos (Kaili) dan wilayahwilayah Poso serta Tojo yang termasuk dalam wilayah Keresidenan Manado; Di sebelah timur dengan wilayah Tobungku dari Keresidenan Temate, Laiwui atau Kendari dan Poleang. Kemudian sepanjang pantai selatan dibatasi oleh Teluk Bone. .... Luhu dibagi dalam wilayah-wilayah: Mangkoka atau Bingkoka, Lelewau, Ussu, Wotu, Baebunta Pongrang, Rongkong, Sengkong, Seko Buwa, Olang, 
Masamba, Walenrang, La Rompang, Suling, Cimpu dan Bariko. .... Selanjutnya termasuk wilayah Luhu yaitu hampir semua suku Toraja atau negeri-negeri di Sulawesi Tengah di antaranya ialah: Pajungallo, Uraso atau Karre, Pantilang, Rantebuwa, Maliang, Lembang dan Batu-alu; semuanya terletak di selatan Baratdaya Palopo;- dan Buntu, Nangalla, Batang, Pambulang, semuanya terletak di sentral Sulawesi...... Apabila negeri Toraja meliputi luas 500 mil persegi dan setiap mil persegi 300 orang, maka penduduk Toraja akan berjumlah 150.000 jiwa. Oleh karena itu di Luhu terdapat penduduk yang terdiri atas: 1. Penghuni pantai 22.500 jiwa, 2. Di Ibukota Palopo 10.140 jiwa, 3. Di Pulau Palopo 400 jiwa, 4. Di Mengkoka 3600 jiwa, dan di Toraja 150.000 jiwa. Jumlah seluruhnya 186.640 jiwa, di antaranya 36.400 jiwa orang Bugis (Mappasanda dan Hafid, 1993)

Mencermati pemberitaan Morris (1888) di atas, Paling tidak ada tiga hal menarik yang penting untuk dicatat. Pertama, Kedatuan Luwu menguasai wilayah cukup luas dengan topografi yang sangat bervariasi. Kedua, estimasi jumlah penduduk dimana Suku Toraja jauh melebihi suku lain termasuk Suku Bugis yang memegang pemerintahan. Ketiga, terdapat beberapa jenis etnis yang menyangga Kedatuan Luwu. Bila gambaran geografi, demografi dan etnisitas tersebut dijadikan rujukan untuk menimbang neraca penelitian yang selama ini dilakukan, tampaknya spektrum penelitian belum menyentuh pada Kedatuan Luwu secara representatif.

Untuk mulai merambah ke arah tersebut, pertanyaan penelitian mungkin dapat dimulai dengan bagaimana peranan komunitas non Bugis atau terutama komunitas berbudaya Toraja dalam menunjang kedatuan Luwu ataukah sejauh manapenelitian diarahkan pada pengungkapan sejarah Kedatuan Luwu yang lebih komprehensif, tidak hanya pada sejarah yang dilakonkan oleh suku Bugis, kalau kita risih menyebutnya sebagai sejarah kaum istana. Berangkat dari pemikiran ini, saya ingin mengajukan beberapa cuplikan data arkeologi hasil peninggalan komunitas berbudaya Toraja. Mudah-mudahan uraian data di bawah dapat menambah wawasan kita tentang kompleksnya aspek historiografi Kedatuan Luwu, tidak sesempit permasalahan di teritori Kota Palopo saja yang telah menjadi pengetahuan populer di Sulawesi Selatan. 


\section{Data Arkeologi}

Komunitas berbudaya Toraja selain mengokupasi wilayah yang termasuk administratif Tana Toraja sekarang dengan topografi bergelombang lemah dan keras, juga mengokupasi wilayah-wilayah yang termasuk dalam Kabupaten Luwu misalnya Walenrang, Lamasi, Belopa, Sa'bang, Masamba, Seko, Larompong, Ponrang, Rongkong, Bastem, Battang dan masih banyak daerah lain. Komunitas berbudaya Toraja di daerah tersebut tidak mengetahui kapan daerah ini diokupasi oleh nenek moyang mereka dan berdasarkan informasi yang diperoleh, diketahui bahwa daerah-daerah tersebut memiliki peninggalan arkeologis yang diklaim sebagai leluhur mereka. Beberapa kelompok komunitas juga masih mempraktekkan tradisi nenek moyang mereka sampai sekarang. Berikut akan diuraikan deskripsi beberapa peninggalan komunitas berbudaya Toraja di Luwu yang berhasil dihimpun meskipun sama sekali tidak merepresentasikan semua data yang ada.

\section{- Situs Penguburan di Kecamatan Walenrang}

Kecamatan Walenrang sekarang masuk dalam wilayah Kotamadya Palopo. Lingkungan sekitar situs merupakan daerah pegunungan kapur dan lembah serta hutan. Masyarakat setempat mengokupasi lembah, dataran dan lereng gunung yang subur. Dua desa yang saya jadikan lokasi penelitian adalah Desa Ilanbatu dan Desa Tombang. Bahasa Toraja digunakan sebagai bahasa sehari-hari oleh masyarakat setempat dengan pola mata pencaharian pertanian dan pencarian hasil hutan. Tumbuhan yang dibudidayakan adalah padi, kopi, cengkeh, durian dan coklat. Cerita Rakyat yang berkembang selalu mengaitkan masyarakat setempat dengan daerah asal mereka dari Toraja. Sebagian besar masyarakatnya juga masih memiliki hubungan keluarga dengan masyarakat Toraja. Alam pikiran dan kepercayaan mereka identik dengan sistem alam pikiran dan kpercayaan masyarakat Toraja. Masyarakat setempat tidak lagi mengetahui sejak kapan nenek moyang mereka mengokupasi daerah tersebut.

Ada dua gua yang berhasil didata di masing-masing desa yang saya survei. Pertama adalah dua gua di Desa Tombang yang tidak diketahui namanya oleh masyarakat setempat dan kedua adalah Gua Batawase di Desa Ilanbatu. Dua gua di Desa Tombang kondisinya tidak terawat, lembab dan temuan arkeologis di 
dalamnya sudah rapuh dan banyak yang hancur tidak teridentikasi lagi. Gua pertama mulutnya berorientasi ke tenggara dan mulut gua kedua berorientasi ke barat. Artefak yang ditemukan berupa wadah kubur, fragmen tempayan, fragmen tembikar, keramik asing, pisau, parang, tombak, batu penumbuk dan rincingrincing. Meskipun sudah rusak berat, fragmen wadah kubur masih dapat diidentifikasi yaitu menyerupai bentuk erong tipe perahu di Tana Toraja. Temuan non artefak berupa tulang manusia dalam bentuk fragmentaris, gigi manusia, kerang dan gigi hewan (Sori, 1995:29-46).

Menurut informan, dahulu juga terdapat barang emas, perunggu dan keris tetapi dicuri oleh orang yang tidak bertanggung jawab. Juga diceritakan bahwa tempayan yang pecah berisi kerangka manusia beserta beberapa benda lain terbuat dari emas, perunggu dan besi. Konon kedua gua ini digunakan untuk penguburan Puang Massawae dan pengikutnya. Puang Massawae adalah tokoh dalam cerita rakyat setempat yang digambarkan memerintah daerah tersebut berkat kelebihannya karena memiliki kekuatan supra natural.

Mengamati konteks temuan dan membandingkan dengan beberapa data arkeologis yang sejenis, kita tidak punya keraguan untuk mengatakan bahwa kedua gua ini telah difungsikan sebagai tempat penguburan. Bila melihat tingginya tingkat kerusakan data artefak dan non artefak, kita juga tidak dapat membuat estimasi tentang berapa jumlah populasi yang dikubur di dua gua ini karena tidak dapat diketahui berapa sampel data yang sudah hancur dan hilang. Namun bila kita mengandaikan satu buah parang diikutkan pada satu mayat, maka jumlah populasi

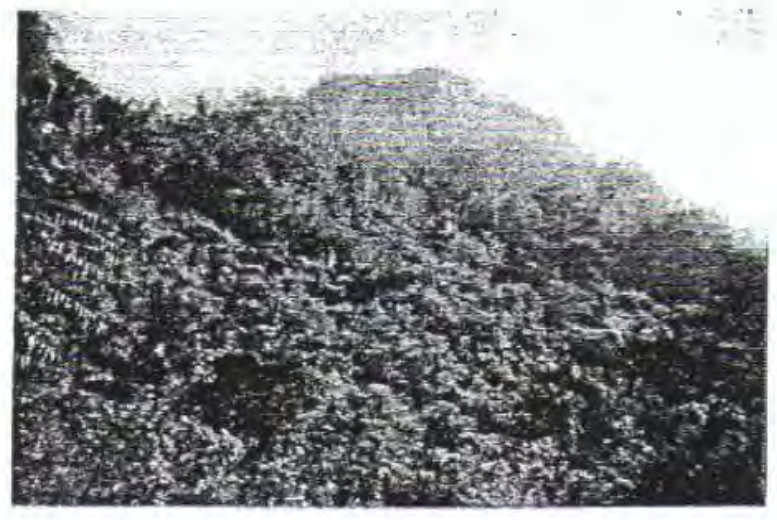

Gunung dan vegetasi Situs Batawase

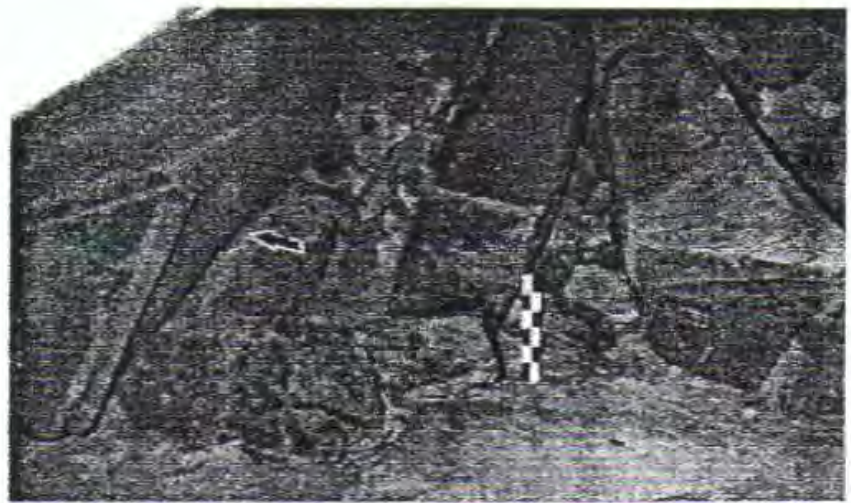

Duni yang telah lap̧uk di Sjtus Batawase 
yang dikubur pada kedua gua tersebut adalah 127 buah. Tentunya estimasi ini tidak dapat dijadikan patokan karena tingginya unsur tafonomi dan vandalisme.

Di Desa Ilanbatu, disurvei satu gua dimana informasinya diperoleh dari penduduk setempat. Masyarakat setempat menamai gua tersebut gua Batawase. Secara garis besar, temuan arkeologis pada gua ini identik dengan temuan yang ada di Desa Tombang. Dapat diuraikan jenis temuan artefak sebagai berikut, wadah kubur (erong), parang, pisau, tombak, gelang kerang, gelang perunggu, keramik asing, tembikar dan tempayan. Data non artefaktual berupa kerangka manusia, gigi dan kerang (Tanwir,1995:33-42).

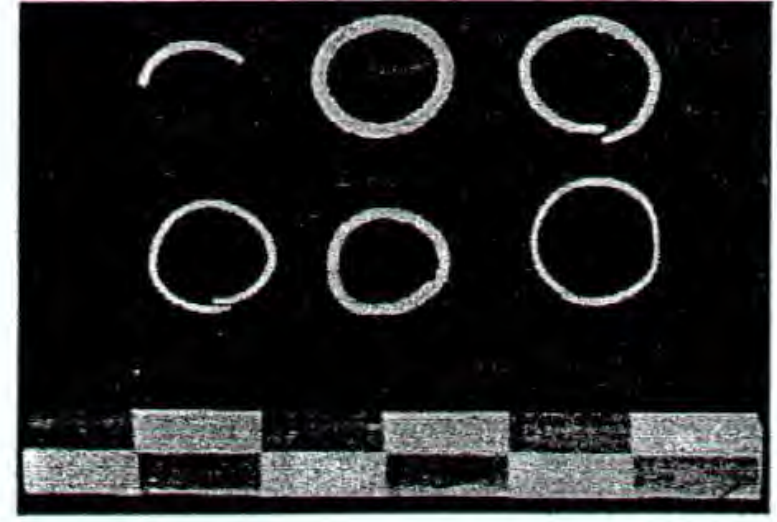

Gelang Perunggu dari Situs Batawase

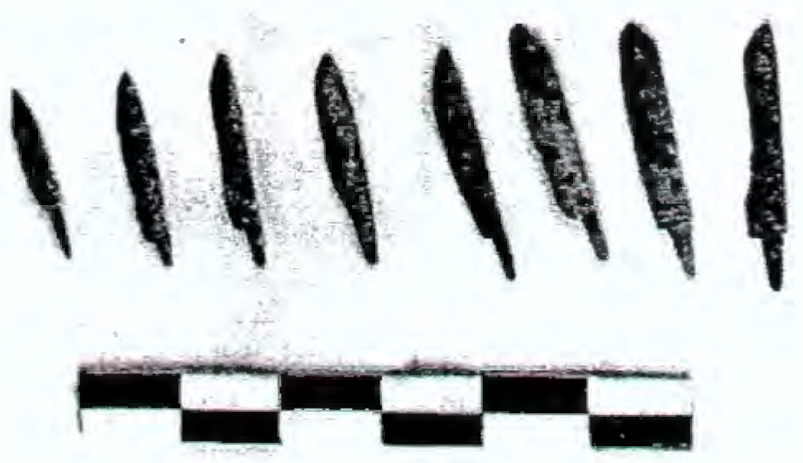

Parang Yang Terlapisi Karat Di Situs Batawase

Beberapa hal yang agak berbeda adalah wadah kubur dimana pada Gua Batawase meskipun juga sudah rusak tetapi masih dapat diamati bentuknya. Bentuknya sangat mirip dengan erong yang banyak ditemukan pada gua penguburan di Toraja yaitu bentuk perahu dan bentuk kerbau. Perbedaan lain yang lebih penting adalah kuantitas temuan. Karena temuan terutama parang dan pisau sangat banyak tertimbun, bercampur dengan temuan lainnya maka tidak dapat dihitung jumlahnya. Tetapi bila kita membuat estimasi jumlah parang saja, mungkin lebih banyak empat kali dari pada jumlah parang yang ada pada dua gua di Desa Tombang. Dan bila setiap parang diikutkan pada satu mayat dan dijadikan indikator untuk mengetahui jumlah populasi yang dikuburkan maka kita memperoleh angka empat kali lebih banyak populasi yang dikuburkan di gua Batawase dari pada di Desa Tombang. 


\section{- Situs Pemukiman di Kecamatan Belopa}

Salah satu situs pemukiman yang terdapat di Kecamatan Belopa Kabupaten Luwu adalah situs pemukiman Lebani, di Desa Lebani. Tepatnya adalah puncak gunung Lebani. Lereng dan lembah di kaki Gunung Lebani merupakan areal persawahan dan perkebunan masyarakat setempat. Sekarang, situs Lebani sudah tidak lagi diokupasi. Masyarakat lebih memilih areal yang lebih rendah dan dekat dengan akses jalan desa. Walaupun demikian, situs ini masih dikeramatkan sampai sekarang. Jarak situs ke jalan desa adalah $1,5 \mathrm{~km}$.

Secara umum temuan yang didapatkan pada situs pemukiman Lebani adalah batu pemujaan (monolit), kursi batu, lumpang batu, sumur batu, batu datar, tungku, liang batu, fragmen tembikar dan fragmen keramik asing. Temuan-temuan tersebut terdistribusi di puncak sampai lereng gunung Lebani (Sila, 1998:28-47).

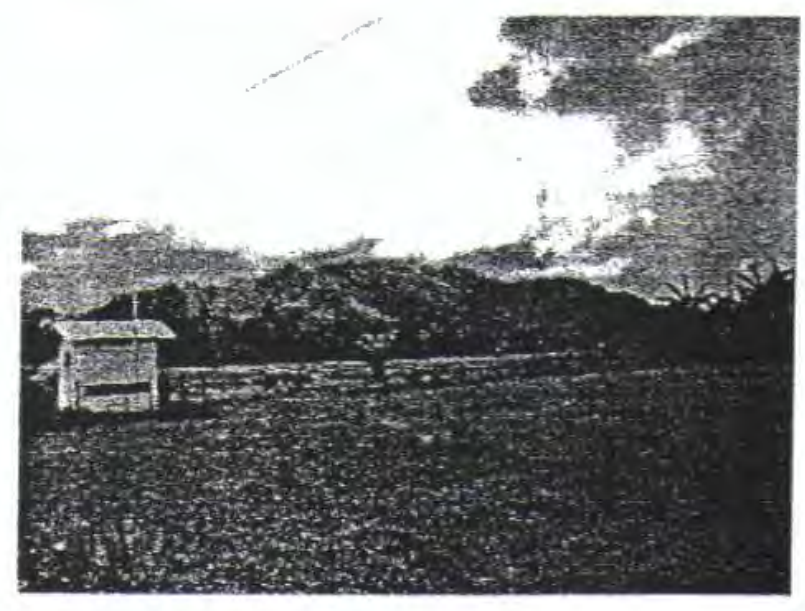

Bukit Lebani dilihat dari arah Timur

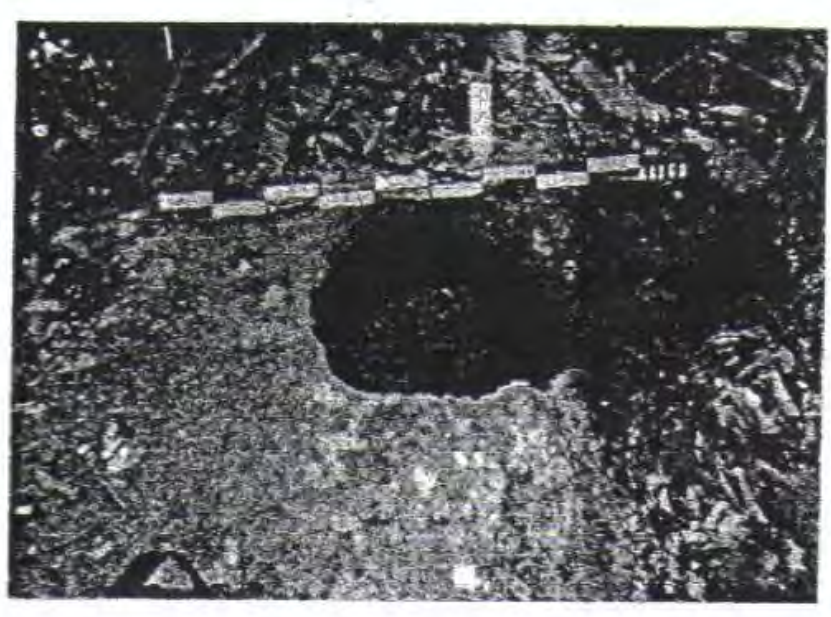

Lumpang batu di Situs Lebani

Batu pemujaan ditemukan dua buah, tidak memperlihatkan ciri artifisial pada permukaan tetapi sangat mungkin sengaja diletakkan karena posisinya yang berdiri. Tinggi batu pemujaan pertama adalah $130 \mathrm{~cm}$ dan batu pemujaan kedua $110 \mathrm{~cm}$. Jarak kedua batu pemujaan tersebut adalah 11 meter. Kedua batu pemujaan ini terletak di bagian pinggir dari permukaan puncak gunung Lebani.

Kursi batu yang didapatkan satu buah dengan posisi agak miring. Bentuknya seperti kursi lengkap dengan sandaran punggung dan sandaran tangan. Mengamati 
permukaannya, batu ini memperlihatkan ciri-ciri artifisial, diperlihatkan pada permukaan bagian tempat duduk dan sandaran tangan. Tinggi $90 \mathrm{~cm}$, lebar $58 \mathrm{~cm}$.

Artefak yang sangat menonjol adalah lumpang batu yang jumlahnya 30 buah dengan jumlah lubang bervariasi, ada yang satu lubang dan ada yang jumlahnya dua puluh sembilan lubang. Jumlah semua lubang dari 30 bongkahan batu tersebut adalah 98 buah lubang. Diameter rata-rata $35 \mathrm{~cm}$ dengan kedalaman rata-rata 30 $\mathrm{cm}$. Lumpang batu berada di bagian puncak dan lereng gunung Lebani.

Sumur batu ada dua buah dengan kedalaman kurang lebih satu satu meter. Bagian atas diberi susunan batu, berfungsi sebagai penahan agar bagian pinggiran tidak runtuh. Bentuk lubang sumur pertama segi empat dengan ukuran panjang $150 \mathrm{~cm}$ dan lebar $105 \mathrm{~cm}$. Sumur kedua yang bentuk lubangnya bundar berdiameter $90 \mathrm{~cm}$.

Batu datar terletak di bagian puncak gunung, bagian dasarnya tertancap ke dalam tanah. Tidak terlihat bukti-bukti artifisial pada permukaan, tetapi masyarakat setempat menyebutnya sebagai bagian dari semua peninggalan yang ada di puncak gunung Lebani. Permukaan datar dengan bentuknya yang alami, panjang $150 \mathrm{~cm}$ dan lebar $120 \mathrm{~cm}$.

Tungku yang dimaksudkan adalah susunan batu alam dimana bagian atas dapat dijadikan dudukan wadah di atasnya. Bagian bawah terdapat rongga, tempat kayu yang terbakar. Yang menarik dari tungku ini adalah letaknya yang berdekatan dengan batu pemujaan, sumur batu dan batu berlubang serta sekitamya banyak ditemukan tembikar.

Liang batu merupakan temuan yang sangat menarik karena liang tersebut merupakan tebing batu yang dipahat persegi hingga membentuk ruang. Di dalam ruang ditemukan tengkorak manusia dan fragmen tulang berserakan. Letak liang batu ini di bagian lereng gunung sebelah timur dengan jumlah liang tiga buah. Ukuran sisi ruang liang pertama adalah $120 \mathrm{~cm}$ dengan tinggi $80 \mathrm{~cm}$. Ukuran sisi ruang liang kedua tidak diketahui karena ditutup oleh masyarakat, sedangkan sisi ruang 
liang ketiga sama dengan ukuran liang pertama. Sepintas, penguburan liang batu mengingatkan kita pada objek wisata Lemo, Londa dan Tampang Allo di Toraja.

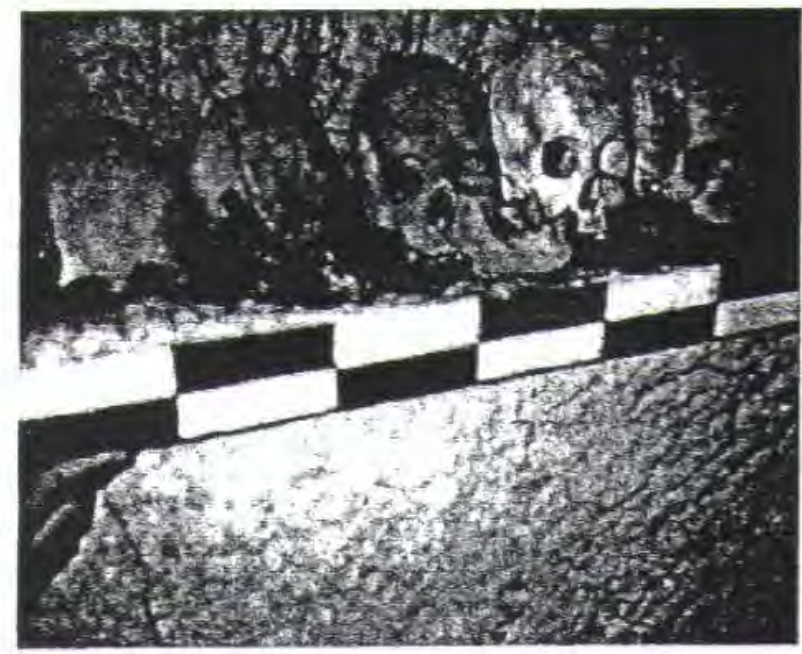

Tengkorak dalam liang di Situs Lebani

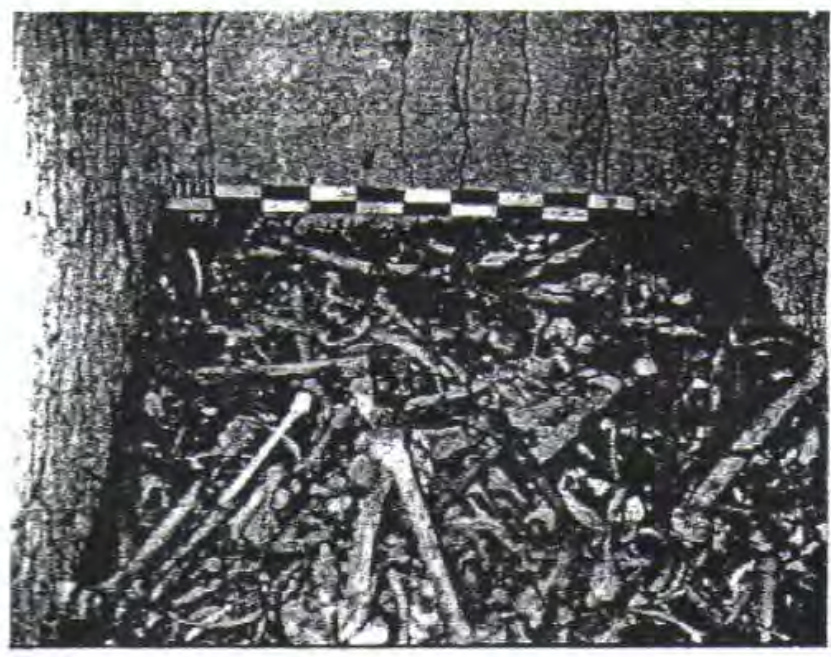

Fragmen Tulang dalam liang di Situs Lebani

Temuan yang cukup signifikan adalah tembikar yang jumlahnya cukup banyak. Yang berhasil ditemukan 677 buah fragmen yang semuanya polos dengan tekstur kasar. Warna bahan adalah merah dan coklat serta coklat kehitam-hitaman. Beberapa fragmen yang dapat direkonstruksi berbentuk wadah tempayan, mangkuk, periuk, piring dan kuali. Temuan keramik asing yang ditemukan hanya 4 buah.

\section{- Situs Mangkaluku Kecamatan Sa'bang}

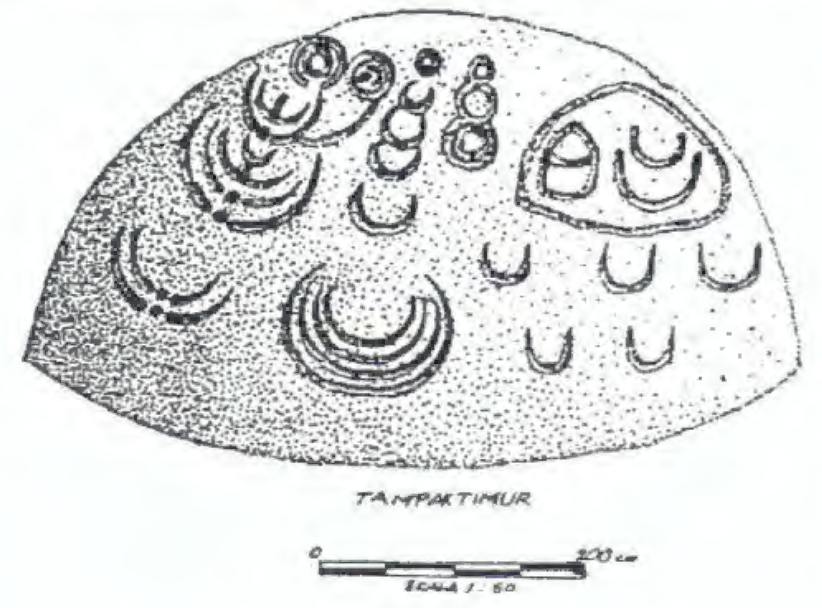

Gambar batu bergores di Situs Mangkaluku

Situs Mangkaluku Kecamatan Sa'bang memiliki variasi temuan yang kurang. Ada tiga jenis artefak yang ditemukan yaitu batu bergores, menhir dan batu berlubang. Batu bergores yang ditemukan hanya satu buah, berupa monolit yang berbentuk lonjong dengan ukuran diameter $630 \mathrm{~cm}$ dan tinggi 270 $\mathrm{cm}$. Letaknya dipinggir sungai Binuang, sekitar $2 \mathrm{~km}$ dari areal pemukiman Desa 
Mangkaluku. Goresan pada permukaan batu berupa tujuh buah goresan berbentuk bulat telur, tiga buah goresan menyerupai bentuk hati, tiga buah goresan berbentuk bulan sabit, enam buah goresan berbentuk tanduk kerbau, satu buah goresan berbentuk mahkota bunga, satu buah goresan berupa tiga bulatan berantai, dua goresan berbentuk spiral atau garis-garis lengkung yang berantai. Kedalaman goresan $2 \mathrm{~cm}$ sampai $5 \mathrm{~cm}$. Selain goresan, juga terdapat lubang-lubang kecil berjumlah 30 buah. Dari bentuk goresan, ini mengingatkan kita pada ornamenornamen yang sering dipakai oleh orang Toraja seperti tanduk kerbau (Yusriadi,1999:15-19).

Batu berlubang yang ditemukan berjumlah lima buah, letaknya tidak jauh dari pinggir sungai Binuang. Ukuran batuan bervariasi dengan jumlah lubang pada permukaan berbeda-beda, ada yang berjumlah 28 buah dan ada yang 74 buah. Tidak ada pola dalam penempatan lubang. Ukuran diameter lubang berkisar 5 sampai $10 \mathrm{~cm}$ dengan kedalaman $2-4 \mathrm{~cm}$. Sedangkan temuan menhir, jumlahnya hanya dua buah yang letaknya juga tidak jauh dari batu berlubang. Menhir tersebut terletak pada undakan kedua dari tiga undakan batu. Ada kesan kedua menhir ini mengapit jalan masuk ke dalam lokasi teras berundak. Tinggi masing-masing menhir 1 meter.

\section{Diskusi dan Perspektif Penelitian Mendatang}

Tiga situs arkeologi hasil budaya komunitas Toraja yang diuraikan di atas adalah sedikit dari sekian banyak situs sejenis yang diinformasikan tersebar di teritori Kedatuan Luwu. Memang disadari bahwa data di atas memiliki kelemahan yang sangat mendasar yaitu tidak disertai dengan pertanggalan, tetapi uraian data dengan penekanan pada dimensi bentuk dan ruang saja mudah-mudahan dapat menggining ilustrasi kita untuk sampai pada kesimpulan bahwa komunitas berbudaya Toraja memang eksis dan memberi peran pada Kedatuan Luwu.

Ada dua aspek yang saya coba soroti dari data yang telah diuraikan, Pertama adalah aspek bentuk (form aspect) dan kedua adalah aspek keruangan (spatial aspect). Dari segi bentuk artefak, beberapa yang menarik perhatian adalah artefak keramik, tembikar, perunggu dan besi. Keramik sudah pasti merupakan barang 
import dan artefak lain yang berasal dari sentra industri di teritori Luwu sendiri hampir dapat dipastikan telah melalui proses pertukaran atau perdagangan dalam distribusinya. Pada prinsipnya, dengan data ini saja, kita dapat mengatakan bahwa interaksi yang panjang dan kontinyu telah terjalin antara satu komunitas dengan komunitas lain atau dengan pedagang dari luar pulau.

Bila diasumsikan bahwa proses interaksi melibatkan energi, waktu, komoditas dan keanekaan lain maka pada saat yang bersamaan, interaksi tersebut juga adalah sebuah mekanisme yang memungkinkan terjadinya alih pengetahuan, alih ideologi, akulturasi atau perubahan budaya. Beberapa sumber tentang hubungan komunitas berbudaya Toraja dengan komunitas Bugis mendukung asumsi di atas. Dapat disebutkan misalnya alih pengetahuan yang dikisahkan dalam cerita rakyat pengrajin besi Massepe (Kabupaten Sidrap). Dikisahkan dengan tegas bahwa pertalian asal usul keterampilan menempa besi di Massepe berasal dari orang Toraja (Sangalla) bernama Panre Bakka (Isa,1979,54-55). Lebih jauh, Chritian Pelras menyatakan bahwa menurut orang Bugis sendiri, sejumlah kerajaan Bugis didirikan oleh bangsawan Toraja (Pelras,2006:18). Dalam prosesi upacara Rambu Solo Di Toraja yang sangat populer, kehadiran bangsawan Luwu sangat penting artinya karena dianggap bahwa mereka (suku Bugis dan Toraja) memiliki hubungan geneologi (komunikasi personal dengan Akin Duli tanggal 27 Juli 2006).

Tambahan data lain adalah selembar kain sutra India dari Toraja akan melebarkan pembicaraan kita bukan hanya pada komoditas tetapi juga pada salah satu jalur perdagangan di Kedatuan Luwu. Kain sutra tersebut setelah dianalisis secara laboratoris berasal dari abad ke-15. Campbell Macknight mengklaim bahwa kain sutra tersebut telah dipertukarkan dengan emas dari Torajamelalui sungai Rongkong. Sungai Rongkong merupakan salah satu jalur penting yang menghubungkan komunitas pesisir dan dataran rendah dengan komunitas Toraja di daerah pegunungan. Kain sutra tersebut dibeli dari pemiliknya dan sekarang disimpan pada salah satu museum di Camberra, Australia (komunikasi personal dengan Campbell Macknight, 20 Juli 2006). 
Secara spatial, data yang menarik adalah distribusi toponim berbudaya Toraja yang mengelilingi pusat Kedatuan Luwu. Toponim-toponim yang diokupasi oleh orang Toraja (tahun 1888 berjumlah 150.000 jiwa) secara garis besar memiliki karakter topografi bergelombang kuat (pegunungan) sedangkan orang Bugis yang berjumlah 36.400 jiwa pada tahun yang sama, mengokupasi daerah pesisir dan dataran rendah. Potensi wilayah komunitas berbudaya Toraja tersebut berdasarkan data arkeologis meliputi besi, damar dan emas. Khusus untuk besi, telah diidentifikasi beberapa sentra industri yaitu sekitar Danau Matano, Limbong, Seko dan hulu Sungai Kalaena (Sarjianto,2000:96). Damar yang merupakan komoditas kedua berasal dari hutan, juga eksploitasinya dilakukan oleh komunitas berbudaya Toraja. Sedangkan emas sudah diketahui berasal dari Tana Toraja (komunikasi personal dengan Campbell Macknight, 20 Juli 2006).

Dapat dikatakan bahwa komoditas perdagangan yang dikontrol oleh Kedatuan Luwu bersumber dari komunitas berbudaya Toraja. Selain sebagai pemegang pemerintahan, komunitas Bugis mengambil peran sebagai middleman, mengantarai perdagangan antara pedagang luar Luwu dengan komunitas Toraja yang indigenous. Berkembangnya nilai hidup telah menjadi pemicu ramainya perdagangan pada masa itu. Peralatan yang dibutuhkan dalam segala aspek hidup semakin berkembang dan kondisi ini semakin menghidupkan Kedatuan Luwu sebagai penerima pajak perdagangan. Yang perlu digarisbawahi adalah industri besi. Penguasaan Kedatuan Luwu atas industri besi yang dieksploitasi oleh komunitas berbudaya Toraja merupakan kemajuan signifikan yang menempatkan Luwu dalam historigrafi Nusantara. Mengenai pentingnya logam dalam hidup manusia, Childe mencatat bahwa logam merupakan landasan utama bagi fungsi-fungsi teknoekonomi maupun sosio-teknik untuk berkembangnya peradaban (Childe,1972:42). Keahlian metalurgi juga dapat dicatat sebagai kemajuan signifikan dalam peradaban manusia karena merupakan puncak perkembangan pyrotechnology.

Dari penjelasan tentang hubungan budaya antara Toraja dan Bugis di atas, kita sampai pada hipotesis bahwa semua wilayah yang termasuk dalam teritori Luwu memiliki peranan yang penting dalam menunjang Kedatuan Luwu. Melihat wilayahnya yang luas dengan beberapa suku yang menunjangnya juga bervariasi, 
tentunya proses kebudayaan yang telah terjadi dalam beberapa abad pertumbuhannya sangatlah kompleks. Mementaskan kembali sejarah Kedatuan Luwu dengan keterbatasan data dan perspektif adalah hal yang jauh dari kemungkinan. Tampaknya, perspektif istana yang banyak mengilhami ilmuan tidak lagi tepat untuk diterjemahkan dalam langkah-langkah penelitian secara teknis.

Melihat pentingnya segala aspek dalam lingkup Kedatuan Luwu, untuk ancangan penelitian ke depan ditawarkan tiga rekomendasi. Pertama, lokasi penelitian mungkin dapat dilebarkan ke daerah pegunungan, bukan hanya pada dataran rendah atau istana Kedatuan Luwu. Kedua, mengingat keterbatasan bila berjalan sendiri, hendaknya filolog, arkeolog, sejarawan, geolog, kimiawan dan ilmu bantu yang dianggap dapat memberikan kontribusi bisa bekerja bersama secara terpadu. Ketiga, analisis arkeometri sangat diperlukan mengingat bertumpuknya pertanyaan yang sifatnya hipotetik belum bisa diungkap sampai sekarang.

* Penulis adalah Dosen Jurusan Arkeologi Universitas Hasanuddin, Makassar. Sekarang melanjutkan studi pada Jurusan Arkeologi Universitas Gadjah Mada.

\section{DAFTAR PUSTAKA}

Caldwell, I.A. 1995. ower, State, and Society among the Pre-Islamic Bugis", Bijdragen tot de Taal-, Land-en Volkenkunde,151,pp. 325-342.

Caldwell, I.A. 1998.'The Chronology on the King List of Luwuq to A.D. 1611", paper Submitted on South Sulawesi History and Culture, Camberra: ANU-Arsip Nasional.

Caldwell, I.A. 2003. Kenyataan, Anakronisme dan Fiksi : Arkeologi Bersejarah dan Pusat-pusat Kerajaan dalam La Galigo, dalam Nurhayati rahman, Anil Hukma dan Idwar Anwar (eds.), La galigo : Menelusuri Jejak 
Warisan Dunia, Pusat Studi La Galigo Unhas, Makassar/Kabupaten Barru. 2003: 449-458.

Childe, Gordon. !972. "Th'e Urban Revolution”, dalam Mark Loan (ed.), Contemporary of Archaeology A guide to Theory and Contribution, London. Sorthern Illionis University Press, fetter Smers Inc.

Fadillah, Moh. Ali dan Sumantri, Iwan. 2000. Kedatuan Luwu, Perspektif Arkeologi, Sejarah dan Antropologi. Lembaga Penerbitan Universitas Hasanuddin. Makassar.

Isa, Sulaiman. M. 1979. Dari Gecong Hingga ke Rotary: Perkemangan Usaha Kerajinan Pandai Besi Massepe. Ujung Pandang: Stencil PLPIIS.

Mahmud, Irfan, 2002. Kota Kuno Palopo, Dimensi Fisik, Sosial dan Kosmologi, Ujung Pandang, Masagena Press.

Mappasanda,Ham dan Hafid, Muh. Yunus. 1992. 1992/1993. Kerajaan Luwu (menurut Catatan D.F van Braam Morris), Ujung Pandang: Balai kajian sejarah dan Nilai tradisional , Departemen Pendidikan dan kebudayaan.

Pelras, Christian. 2006. Manusia Bugis. Nalar. Jakarta.

Sarjianto. 2000. Kedatuan Luwu Pra-lslam : Eksploitasi Sumber-sumber Produksi dalam Kedatuan Luwu, Perspektif, Arkeologi, Sejarah dan Antropologi. Lembaga Penerbitan Universitas Hasanuddin. Makassar.

Sila, Munir. 1998. Situs Gunung Lebani Kecamatan Belopa Kabupaten Luwu, (Studi Pemukiman). Skripsi . Jurusan Arkeologi Fakultas Sastra Universitas Hasanuddin. Makassar. 
Sori, Atto. 1995. Gua Sebagai Wadah Penguburan Pada Situs Tombang, Kecamatan Walenrang, Luwu. Skripsi. Jurusan Arkeologi Fakultas Sastra Universitas Hasanuddin. Makassar.

Tanwir M. 1995. Temuan benda Logam Pada Situs Penguburan Batawase Kabupaten Luwu (Suatu Tinjauan Fungsional). Skripsi. Jurusan Arkeologi Fakultas Sastra Universitas Hasanuddin. Makassar.

Yusriadi, 1999. Makna Batu Bergores Situs Mangkaluku Kabupaten Luwu. Skripsi. Jurusan Arkeologi Fakultas sastra Universitas Hasanuddin. Makassar. 